\title{
May Thorseth: Commentary of the Manifesto
}

\author{
May Thorseth
}

The information abundance and the primacy of interactions over entities is particularly important in dealing with the problem of the public, i.e. the question of how to make the public well informed. The importance of being well informed relates to issues like how to fight intolerance and fundamentalism in particular. Besides, the problem of the public is about education: what foci and what kind of methodologies to apply in teaching younger generations to broaden their perspectives? As an example, a common exercise for school children is to use the Internet to collect information for assignments. As yet, the teaching staff often seems to lack the relevant competencies for guiding their students.

In political contexts the problem of information abundance also needs to be resolved: the temptation to collect information by looking up websites rather than discussing or interacting with political opponents is a threat to the public, particularly to making the public better informed. The case of July 22, 2011 in Norway is but one example of lack of relevant interaction between extremists and their opponents, i.e. more moderate and democratically oriented people. One claim in the aftermath of this event has been that the public has not taken seriously extreme viewpoints as put forth on the Internet. As a result, there has been insufficient public debate.

Another important issue in the Manifesto is about distributed or (lack of) shared responsibility. As no single governmental or non-governmental bodies or other organisations are able to keep control, and information flows are less transparent than before, this seem to have a negative impact on responsibility: no single institutions or individuals can be assigned responsibility as in pre-IT times. Technologies that are gradually substituting human responsibilities endangers individuals' democratic freedoms - thus, there is a need for research to focus on empowering-/disempowering developments resulting from shortage of human interactions.

Another very important issue is the public-private distinction. Rather than speaking in terms of distinction between the two it makes better sense to speak of comple-

\footnotetext{
M. Thorseth $(\bowtie)$

Department of Philosophy, Norwegian University of Science and Technology,

Trondheim, Norway

e-mail: may.thorseth@ntnu.no

L. Floridi (ed.), The Onlife Manifesto,

DOI 10.1007/978-3-319-04093-6_10, (C) The Author(s) 2015
} 
mentary relations between them: home is no longer necessarily a private space as distinct from public spaces. As an illustration, political and public negotiations need not necessarily take place in a public space as Skype is available almost everywhere. And vice versa, when it comes to private conversations they may just as well take place in public space. Further, what is conceived as private or public seems to have changed, too. What used to be considered intimate among young people, like e.g. sexual relations are viewed far less private compared to parents' occupations, or political affiliations of today. Thus, rather than speaking of private versus public there is a need to emphasise the importance of context: whatever is contested in public space is no longer purely private. Globalisation, not least due to the spread of information technology implies a breakdown of any clear cut distinction between private and public. As a consequence there is a need to redefine public and private spaces, most importantly what sense we currently want to make of these categories. As an example it is no longer obvious that the consumption of private households/ individuals is not a public issue when discussing e.g. rights and responsibilities for commons like natural resources. Knowledge is also a commons in this sense, and thus we need to question whether there should be both rights and duties associated with it. Private and public are no longer counterparts, but rather complementary categories being challenged by information and communication technologies.

Consequently, being well informed about societal matters is truly a public matter, as well.

Open Access This chapter is distributed under the terms of the Creative Commons Attribution Noncommercial License, which permits any noncommercial use, distribution, and reproduction in any medium, provided the original author(s) and source are credited. 